Изв. АН Эстонии. Геол., 1991, 40, № 4, 152-159

УДК $551.732(474): 551.7 .022 .2$

Тадас ЯНКАУСКАС*

\title{
БИОСТРАТИГРАФИЯ ПОГРАНИЧНЫХ ОТЛОЖЕНИЙ НИЖНЕГО И СРЕДНЕГО КЕМБРИЯ В ЛИТВЕ
}

Биостратиграфическое расчленение кембрийских отложений ВосточноЕвропейской платформы основано главным образом на данных исследования акритарх (Волкова, 1973; Волкова и др., 1979). Фаунистические остатки здесь редки и используются для датирования лишь отдельных толщ, а также для увязки совместно с ними встреченных комплексов акритарх с трилобитовыми зонами скандинавской шкалы. При этом к настоящему времени наиболее детально исследованы акритархи нижнего кембрия. На уровне переходных отложений от нижнего кембрия к среднему и в среднем кембрии они изучены значительно слабее, главным образом в связи с неполнотой разрезов или с преобладанием не содержащих акритарх песчаниковых толщ.

В последние годы в приморских районах Литвы пробурено несколько глубоких скважин с полным отбором керна по всему кембрийскому интервалу. Приморские разрезы оказались приуроченными к наиболее прогнутой зоне Балтийской синеклизы, они наиболее мористы по сравнению с другими разрезами Литвы и содержат значительно большее количество прослоев глинистых пород, обогащенных акритархами. Важными обстоятельствами являются также отсутствие перерыва в осадконакоплении между нижним и средним кембрием и возможность послойного изучения акритарх на этом важном стратиграфическом рубеже.

Методологической основой использования акритарх в стратиграфии является их разный таксономический состав на разных возрастных уровнях, отражающий этапность эволюционного развития ископаемого микрофитопланктона. Биостратиграфические границы обычно проводятся там, где появляются отдельные таксоны или их группы, стратиграфически не известные ниже. Биостратиграфически обособленные интервалы разреза традиционно именуются горизонтами. Каждый из них характеризуется только ему присущим комплексом акритарх.

Биозоны отдельных видов акритарх обычно пересекают интервалы двух и более горизонтов, поэтому подобрать для каждого из них видыиндексы возможно не всегда. В связи с этим каждый из горизонтов может быть квалифицирован в качестве биостратиграфической зоны (зоны ассоциации).

Совершенствование схем расчленения разрезов по акритархам связано главным образом с уточнением сведений об уровнях появления отдельных таксонов и выявлением интервалов их наибольшего количественного распространения. Это достигается послойными исследованиями акритарх в отдельных разрезах.

В целях ревизии данных о стратиграфическом распространении акритарх в переходных отложениях от нижнего кембрия к среднему и уточнения положения границ горизонтов, а также состава их комплексов акритарх, автором послойно изучены акритархи скв. Генчяй-4, выбранной ранее (Янкаускас, Сакалаускас, 1989) в качестве стратотипической для свит и серий кембрия Литвы (рис. 1).

* Lietuvos Geologijos Mokslineo Tyrimo Institutas (Литовский научно-исследовательский геологоразведочный институт). 232600 Vilnius, Ševčenkos 13. Liełuva. 


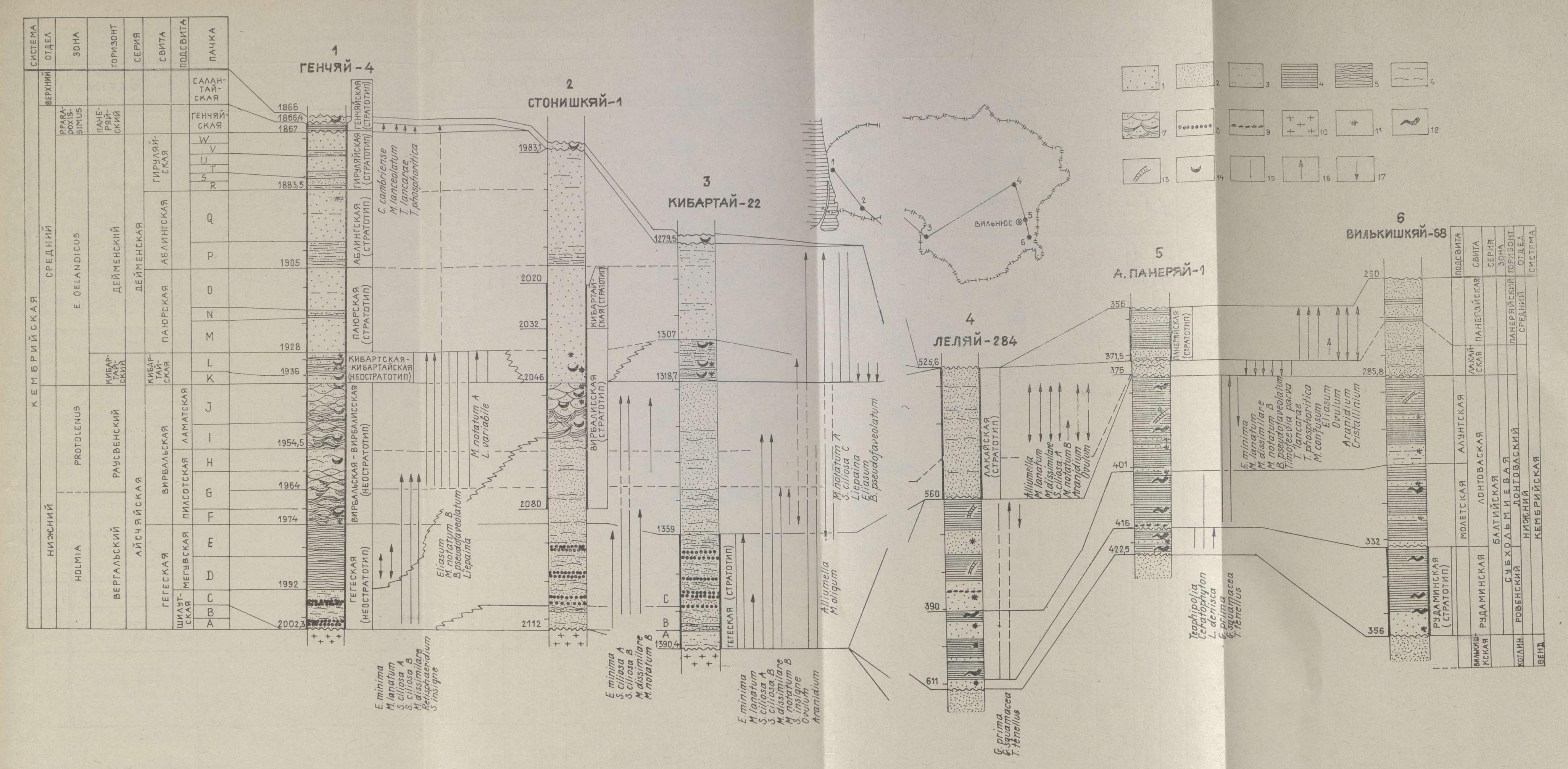

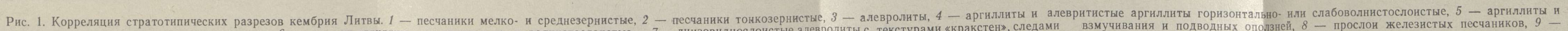
конгломераты, 10 - породы кристаллического фундамента, 11 - глауконит в породе, 12 - сабеллидитиды, 13 - платисолениты, 14 - брахиоподы, 15 - интервал стратраф (17)

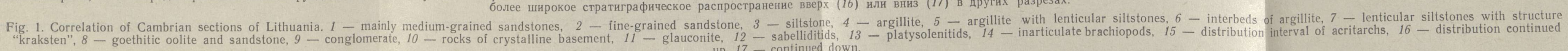




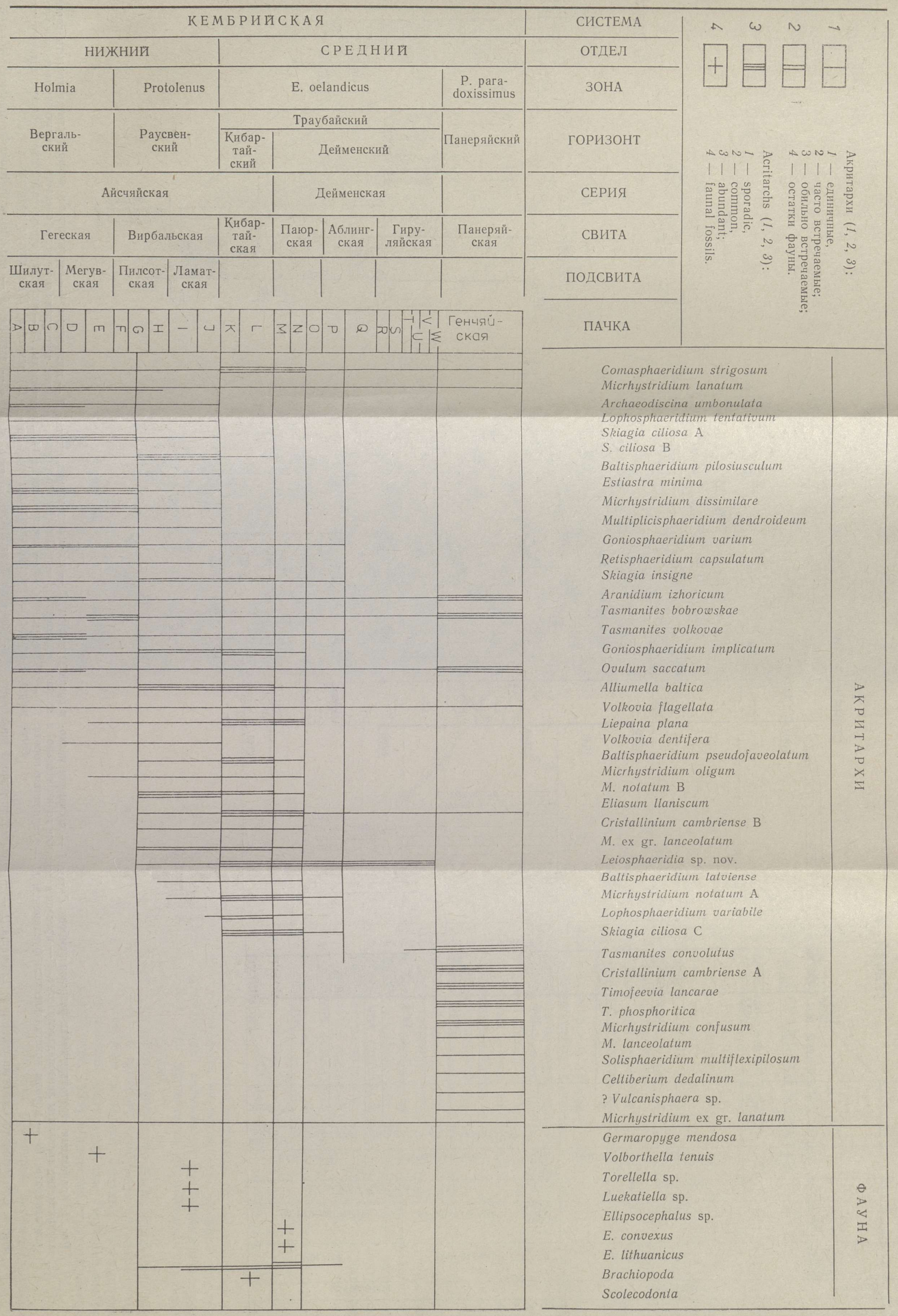


В целом разрез кембрия приморского района Литвы охватывает интервал от верхов трилобитовой зоны Holmia нижнего кембрия до низов трилобитовой надзоны $P$. paradoxissimus включительно. Этот интервал расчленен по акритархам на ряд горизонтов (рис. 1,2 ). Древнейший из них - вергальский - залегает непосредственно на породах кристаллического фундамента. Ему соответствуют гегеская свита и нижние слои вирбальской **. Акритархи вергальского комплекса достаточно полно описаны в литературе (Биркис и др., 1970; Волкова, 1973; Волкова и др., 1979; Янкаускас, 1972, 1980). Новым здесь является обнаружение в его составе некоторых видов акритарх, ранее известных лишь в более молодых отложениях. Один из них Volkovia dentifera (=Deunffia dentifera) впервые описан в качестве вида-индекса уровня зоны Protolenus (Волкова, 1973; Moczydlowska, 1989). Он встречен не только в разрезах Литвы (скв. Пурмаляй-3, глуб. 2318 м), но и в зоне Holmia Польши (скв. Лохув-2, глуб. от 2158 до 2138 м), а также в Британии (Downie, 1982). В верхней части вергальского горизонта спорадически встречаются также Liepaina plana (рис. 1, таблица).

Интервал вергальского горизонта может быть выделен в качестве пик-зоны $M$. dissimilare-E. minima. Здесь эти два вида либо доминируют, либо встречаются значительно чаше, чем стратиграфически выше или ниже.

Кровлю вергальского горизонта (=подошву более молодого раусвенского) предлагаем проводить стратиграфически несколько выше, чем это сделано Волковой (Биркис и др., 1970), - по значительно более яркой биостратиграфической границе, соответствующей уровню появления четко диагностируемого и широко распространенного вида Eliasum llaniscum и сопровождающих его форм (таблица). Выше этой границы доминируют, кроме названного, Liepaina plana Jank. et Volk., Micrhystridium notatum Volk., M. obscurum Volk., Goniosphaeridium implicatum (Fr.), Baltisphaeridium pseudofaveolatum Fr., Retisphaeridium howellii Mart., Alliumella baltica Vand., Skiagia insigne Fr., Baltisphaeridium latviense Volk., Pterospermella vitrea Volk.

Интервал раусвенского горизонта предлагаем выделять в качестве конкурентно-ранговой зоны Eliasum Ilaniscum-Multiplicisphaeridium dendroideum. Биозоны этих видов в целом широки и различны, но они часто перекрываются на интервале раусвенского горизонта и образуют здесь узкую зону их сосуществования.

Стратотипом нижней границы Раусве в уточненном виде предлагаем уровень 1964 м в разрезе скв. Генчяй-4 (Янкаускас, Сакалаускас, 1989) в приморском районе Литвы (рис. 1).

Выбор стратотипа этой границы позволяет более определенно подойти к оценке возраста развитых на востоке Литвы песчаниковых толщ, выделенных в качестве лакайской свиты. По данным автора (Янкаускас, Пашкявичене, 1973), в стратотипическом разрезе последней (скв. Леляй284) присутствуют нижнекембрийские акритархи. Әто положение остается справедливым, но список акритарх может быть несколько уточнен. На глуб. от 544 до 530 м здесь распространены: Micrhystridium lanatum Volk., M. obscurum Volk., M. dissimilare Volk., Alliumella baltica Vand., Skiagia ciliosa B (Volk.), Volkovia dentifera (Volk.), V. flagellata (Jank.), Ovulum saccatum Jank., O. lanceolatum Jank., Tasmanites bobrowskae Waz.

Судя по данным на сегодня, это - раусвенский комплекс.

\footnotetext{
** Здесь и ниже автор применяет новые формы транскрипции на русский язык литовских терминов, которые отличаются от принятых в унифицированной стратиграфической схеме Прибалтики (Решения..., 1978) и в схеме кембрийской системы Русской платформы (Решение ..., 1986), например: раусвеская-раусвенская, дейменаская-дейменская, вирбалисская-вирбальская (примечание Э. Пирруса).
} 


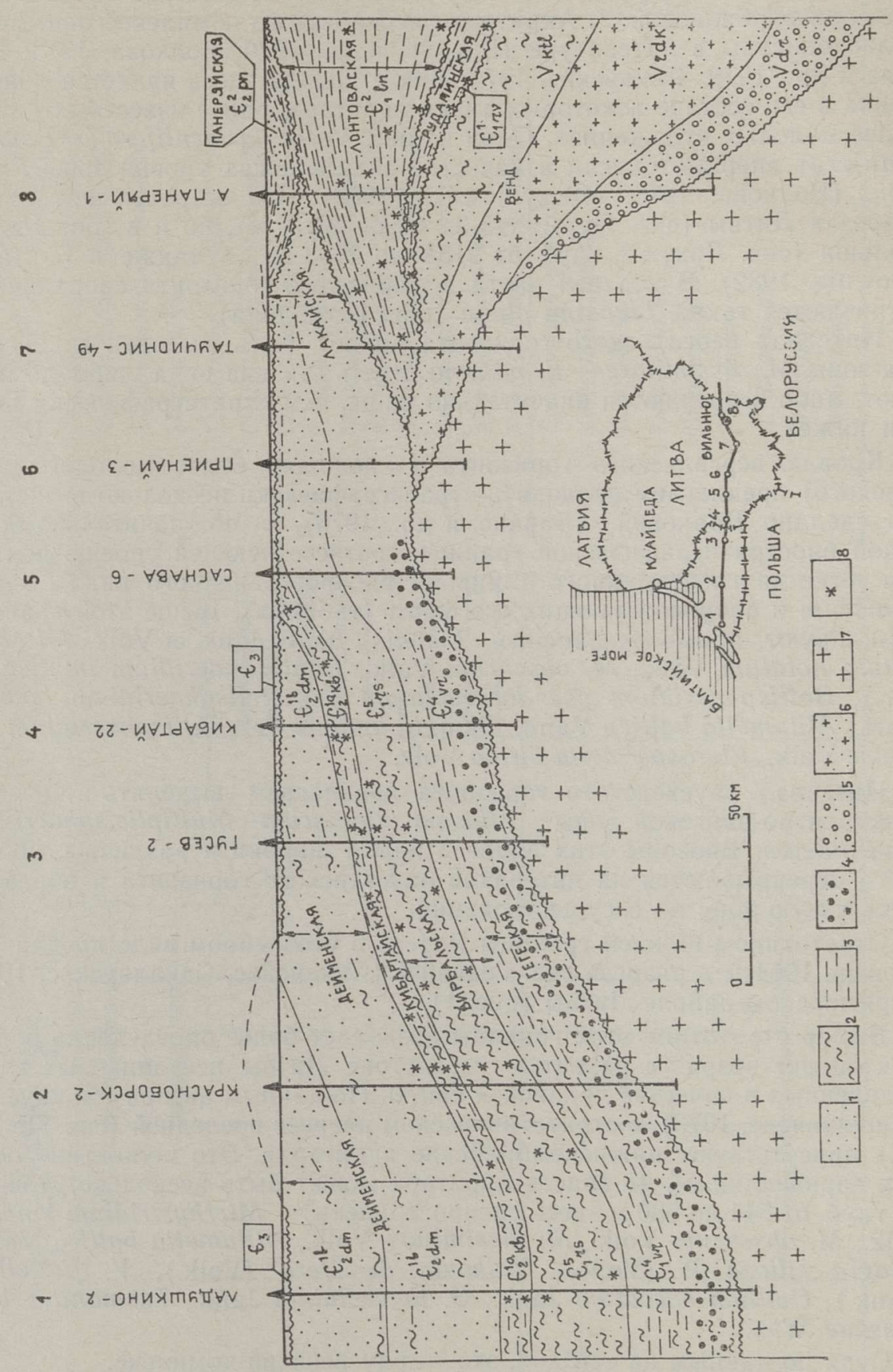


Рис. 2. Палеопрофиль по линии Ладушкино-Вильнюс. 1 - песчаники, 2 - алевролиты, 3 - аргиллиты и глины, 4 - бурые железистые песчаники, 5 - гравелиты песчано-глинистые (мяркисская свита), 6 - песчаники и гравелиты аркозовые, 7 - породы кристаллического фундамента, 8 - глауконит.

Горизонты: $\mathrm{Vdr}$ - древлянский, $\mathrm{Vrdk}$ - редкинский, Vkt1 - котлинский, $\epsilon_{1}^{1} \mathrm{rv}$ - poвенский, $\epsilon_{1}^{2} \ln -$ лонтоваский, $\quad \epsilon_{1}^{4} \mathrm{vr}-$ вергальский, $\epsilon_{1}^{5} \mathrm{rs}-$ раусвенский, $\epsilon_{2}^{1 \mathrm{a}} \mathrm{kb}-$ кибартайский, $\epsilon_{2}^{1 \mathrm{~b}} \mathrm{dm}-$ дейменский, $\epsilon_{2}^{2} \mathrm{pn}-$ панеряйский.

Fig. 2. Cross-section along the Ladushkino-Vilnius line. 1 - sandstone, 2 - siltstone, 3 - argillite and argillaceous rocks; 4 - sandstone with goethitic oolites, 5 - sandyclayey gravelstone (the Merkys Formation), 6 - arkosic sand-and gravelstone, 7 rocks of the crystalline basement, 8 - glauconite.

Stratigraphic indexes of regional stages: Vdr-Drevljany, Vrdk-Redkino, Vktl-Kotlin, $\epsilon_{1}^{1} \mathrm{rv}-$ Rovno, $\epsilon_{1}^{2} \ln$ - Lontova, $\epsilon_{1}^{4} \mathrm{vr}-$ Vërgale, $\epsilon_{2}^{5} \mathrm{rs}-$ Rausve, $\epsilon_{2}^{1 a} \mathrm{~kb}-$ Kybartai, $\epsilon_{2}^{1 \mathrm{~b}} \mathrm{dm}$ - Deimena, $\epsilon_{2}^{2} \mathrm{pn}-$ Paneriai.

Еще одна находка акритарх в составе, близком раусвенскому, известна из разреза скв. Аукштеи Панеряй-1 на глуб. 372 м: Estiastra minima Volk., Archaeodiscina umbonulata Volk., A. bicostata Volk., Micrhystridium dissimilare Volk., M. lanatum Volk., Volkovia dentifera (Volk.), Skiagia ciliosa A (Volk,), Alliumella baltica Vand., Multiplicisphaeridium dendroideum (Jank.), ? Baltisphaeridium pseudofaveolatum Fr., Ovulum saccatum Jank. Этот довольно своеобразный комплекс акритарх расцениваем также как нижнекембрийский. Его своеобразие может быть объяснено условиями формирования в наиболее мелководных прибрежно-морских осадках.

Раусвенские акритархи установлены в разрезе цирмской свиты на востоке Латвии (скв. Лудза-15, глуб. 696 м): Volkovia dentifera (Volk.), Estiastra minima Volk., Baltisphaeridium latviense Volk., Multiplicisphaeridium dendroideum (Jank.), Micrhystridium dissimilare Volk., M. lanatum Volk., Skiagia ciliosa Volk., Retisphaeridium howellii M. et D., Comasphaeridium strigosum Jank., Ovulum saccatum Jank., Aranidium izhoricum Jank. и др. (по Янкаускасу, 1975, с уточнениями).

Граница между нижним и средним кембрием в Литве проводится по подошве кибартайской свиты (Решения..., 1978), среднекембрийский возраст которой обоснован присутствием в ее породах акритарх одноименного комплекса, характерного для надзоны E. oelandicus (Биркис и др., 1970; Волкова, 1973, 1974; Волкова и др., 1979). В разрезах соседней Латвии, находящихся в той же фациальной зоне, встречены трилобиты упомянутой зоны (Стратиграфия .., 1979). В. Коркутисом (1971) в кибартайской свите Литвы установлены беззамковые брахиоподы, имеющие, по его мнению, среднекембрийский возраст. Наконец, укажем на хорошую сопоставимость по составу пород и мощностям прибалтийских и шведских разрезов кембрия (о-в Готланд). При этом уровню кибартайской свиты в Швеции соответствует нижняя часть слоев с E. oelandicus.

- Кибартайский комплекс акритарх в Литве, как и в Прибалтике в целом (Фридрихсоне, 1971; Волкова, 1974; Волкова и др., 1979), отличается от раусвенского иным составом доминирующих видов и резко обедненным видовым составом. В изученных разрезах Литвы доминируют крупные экземпляры Micrhystridium notatum Volk. с хорошо выраженными видовыми признаками (форма А), которым могут сопутствовать два или три тақже многочисленных вида из общего списка доми- 
нантов: Eliasum llaniscum Fomb., Micrhystridium obscurum Volk., Lophosphaeridium variabile Volk., Baltisphaeridium latviense Volk., Retisphaeridium dihamerum S., J. et P., Liepaina plana Jank. et Volk., Comasphaeridium strigosum (Jank.). Единично встречаются Skiagia ciliosa B (Volk.), Annulum squamaceum (Volk.), Goniosphaeridium implicatum (Fr.), Pterospermella vitrea Volk., P. velata Mocz., Retisphaeridium postii (Jank.), Leiovalia tenera Kirj., Skiagia insigne (Fr.) и некоторые другие. Единственный вид Lophosphaeridium variabile Volk. в большом количестве экземпляров присутствует только на уровне кибартайского горизонта, а в наиболее молодых слоях нижнего кембрия можно встретить лишь первых единичных представителей этого вида.

Характерен еще один признак - смена лейосферидиевого фона в препаратах: в нижнем кембрии вездесущие для кембрийских отложений лейосферидии представлены, за редким исключением, тонкостенными формами. На уровне раусвенского горизонта иногда присутствуют в некотором количестве толстостенные формы, которые выше подошвы кибартайского горизонта обычно преобладают. Диаметр оболочек около 30 мкм, толщина стенки - до 3 мкм. Вероятно, это чисто экологическое явление, но для ограниченной территории исследованного региона служит хорошим критерием корреляции.

В разрезе скв. Кибартай-22 в породах кибартайской свиты присутствуют своеобразные Skiagia ciliosa с очень толстой стенкой и очень короткими выростами (форма С). Акритархи такой формы иногда встречаются и в нижнекембрийских отложениях, но там они редки и размеры их меньше.

Таким образом, кибартайский комплекс акритарх, несмотря на его явную унаследованность от раусвенского, имеет ряд специфических черт, позволяющих опознавать его в достаточно насыщенных препаратах.

Верхняя граница распространения кибартайского комплекса акритарх, видимо, чисто экологическая. Перекрывающая кибартайскую свиту песчаниковая дейменская серия насыщена на отдельных стратиграфических уровнях прослоями аргиллитов, содержащих весьма обильный растительный микродетрит и лейосферидии. В нижней половине серии (паюрская свита) в разрезе скв. Вилькичяй-9 на глуб. 1989 м установлены акритархи кибартайского комплекса с преобладанием Micrhystridium notatum Volk. и Eliasum llaniscum Fomb. В единичных экземплярах встречены Lophosphaeridium variabile Volk., Comasphaeridium strigosum (Jank.), Liepaina plana Jank. et Volk., Goniosphaeridium implicatum (Fr.), Pterospermella vitrea Volk., Micrhystridium lanceolatum Vang., Alliumella baltica Vand., Volkovia conifera (Jank.), Cristallinium ex gr. cambriense (Slav.). Акритархи близкого состава встречены также в основании дейменской серии в скв. Поцяй-3 на глуб. 20472037 м совместно с трилобитами Ellipsocephalus convexus Kor. et Jank., E. lithuanicus Kor. et Jank. (Коробов, Янкаускас, 1980) и в скв. Кибартай-30 на глуб. 1268 м - Micrhystridium notatum Volk., Alliumella baltica Vand., Skiagia ciliosa C (Volk.), Leiosphaeridia sp. A.

Таким образом, кибартайский комплекс акритарх распространяется значительно выше кровли собственно кибартайской свиты и теряется внутри «немых» дейменских песчаников, не имея четкой верхней границы. Ранее на это обстоятельство уже указывала Н. А. Волкова (1973). Поэтому и одноименный горизонт пока остается как бы без верхней границы. В этой ситуации мы сохраняем название «кибартайский горизонт» за уровнем собственно кибартайской свиты и ее возрастных аналогов и предлагаем ориентироваться при этом на неостратотип кибартайской свиты в разрезе скв. Генчяй-4, инт. 1936-1928 м (рис. 1). В состав свиты и горизонта не следует включать пачку 14, выделенную в разрезах Латвии (Стратиграфия..., 1979, с. 56). По литологии она ближе более древ- 
ним отложениям, находки среднекембрийских трилобитов приурочены к более молодым слоям.

Интервал палеонтологически слабо охарактеризованных песчаниковых паюрской, аблингской и гируляйской свит, занимающих, однако, большой стратиграфический интервал, выделен в качестве особого дейменского горизонта с типовым разрезом в скв. Генчяй-4, инт. 1928 1867 м. Его отличительная особенность - массовые скопления толстостенных лейосферидий, нитчатых водорослей, в том числе кольчатых Circumiella и акритарх кибартайского комплекса в основании. В гируляйской свите обнаружены акритархи Tasmanites convolutus Volk. et Pisk. Не исключено, что эта свита уже соответствует низам надзоны $P$. paradoxissimus.

Несогласно перекрывающая дейменскую серию генчяйская пачка содержит в чрезвычайно обильном количестве акритархи Timofeevia phosphoritica Vang., T. lancarae (C. et D.), Cristallinium cambriense (Slav.), Micrhystridium confusum (Jank.), Tasmanites bobrowskae Waz., T. convolutus Volk. et Pisk., а также единичные Solisphaeridium multiflexipilosum Slav. (рис. 1).

Акритархи аналогичного состава встречены в разрезе скв. Стумбрес-1 на глуб. 2008 м.

На востоке Литвы этот комплекс акритарх был известен ранее и получил название панеряйского. Он содержится в породах панеряйской свиты и горизонта, стратотипы которых совпадают - скв. Аукштеи Панеряй-1, инт. 371,5-356 м (Янкаускас, 1980). Комплекс здесь богаче. Помимо перечисленных, в его составе присутствуют: Aranidium izhoricum Jank., Ovulum saccatum Jank., Volkovia flagellata (Jank.), Micrhystridium lanatum Volk., M. dissimilare Volk., M. lanceolatum Vang., Comasphaeridium strigosum (Jank.), Skiagia aff. ciliosa (Volk.), Alliumella baltica Vand., Pterospermella sp.

Панеряйский комплекс встречен также в соседней скв. Ячионис-299 (инт. $321-303,8$ м) в буйковской свите Белоруссии (скв. 068, инт. $192-$ 187 м), в веселовской свите Калининградской области (скв. Веселовская-8, инт. $2466-2463$ м).

Имеющиеся сведения о стратиграфическом распространении среднекембрийских акритарх в других регионах мира (Martin, Dean, 1988; Hagenfeldt, 1989; Eklund, 1990) позволяют опустить слои с панеряйским комплексом акритарх на уровень низов надзоны $P$. paradoxissimus среднего кембрия.

Панеряйский горизонт может быть квалифицирован в качестве конкурентно-ранговой зоны Comasphaeridium strigosum-Timofeevia lancarae. Оба вида имеют широкое географическое распространение в Северной Евразии, но их совместное нахождение ограничивается узким стратиграфическим интервалом.

Таким образом, отложения среднего кембрия Литвы расчленены на три горизонта. При этом кибартайский и дейменский имеют близкую палеонтологическую характеристику и могут быть объединены в единый более крупный горизонт (или надгоризонт), который предлагаем именовать траубайским (типовой разрез - скв. Генчяй-4, инт. 1936-1867 м).

Приведенные данные позволяют уточнить сведения о составе акритарх на уровне переходных слоев от нижнего кембрия к среднему (таблица) и подкрепить новыми палеонтологическими данными корреляцию ф.ациально меняющихся разрезов кембрия на переходе от Балтийской синеклизы к северному склону Мазурско-Белорусской антеклизы в пределах территории Литвы (рис. 2). 
Биркис А. П., Брангулис А. П., Волкова Н. А., Розанов А. Ю. 1970. Новые данные по стратиграфии кембрия Восточной Латвии. - Докл. АН СССР, 195, 4, 907-910.

Волкова Н. А. 1973. Акритархи и корреляция венда и кембрия западной части Русской платформы. - Советская геология, 4, 48-62.

Волкова Н. А. 1974. Акритархи из пограничных отложений нижнего-среднего кембрия Западной Латвии. - В кн.: Биостратиграфия и палеонтология нижнего кембрия Европы и Северной Азин. Москва, Наука, 194-198.

Волкова Н. А., Кирьянов В. В., Пискун Л. В., Пашкявичене Л. Т., Янкаускас Т. В. 1979. Растительные микрофоссилии. - В кн.: Палеонтология верхнедокембрийских и кембрийских отложений Восточно-Европейской платформы. Москва, Наука, $7-49$.

Коркутис В. А. 1971. Кембрийские отложения Балтийского бассейна. - Тр. ЛитНИГРИ, вып. 12. Вильнюс, Минтис.

Коробов М. Н., Янкаускас Т. В. 1980. Первая находка трилобитов в среднекембрийских отложениях Южной Прибалтики (Литовская ССР). - Докл. АН СССР, 253, 3, $1184-1188$.

Решение межведомственного регионального стратиграфического совещания по кембрийским отложениям Русской платформы (г. Вильнюс, 1983). 1986. Ленинград.

Решения межведомственного регионального стратиграфического совещания по разработке унифицированных стратиграфических схем Прибалтики, 1976. 1978. Вильнюс-Ленинград.

Стратиграфия верхнедокембрийских и кембрийских отложений запада Восточно-Европейской платформы. 1979. Москва, Наука.

Фридрихсоне А. И. 1971. Акритархи Baltisphaeridium и гистрихосферы (?) из кембрийских отложений Латвии. - В кн.: Палеонтология и стратиграфия Прибалтики и Белоруссии, III. Вильнюс, Минтис, 5-22.

Янкаускас T. B. 1972. Биостратиграфия нижнего кембрия Литвы. - Докл. АН СССР, $205,5,1186-1189$.

Янкаускас T. В. 1975. Новые данные к истории геологического развития территории Прибалтики в кембрийский период. - Изв. АН СССР. Сер. геол., 1, 112-118.

Янкаускас Т. В. 1980. К микрофитологической характеристике средне- и верхнекембрийских отложений северо-западной части Восточно-Европейской платформы. Изв. АН СССР. Сер. геол., 29, 4, 131-135.

Янкаускас T. В., Пашкявичене Л. T. 1973. Новые данные к стратиграфии кембрия восточных районов Литовской ССР. - В кн.: Материалы III научной конференции геологов Литвы. Вильнюс, Периодика, 12-14.

Янкаускас T. В., Сакалаускас В. Ф. 1989. Кембрийские отложения приморского района Литовской ССР. - Науч. тр. ВУЗов ЛитССР. Геол., 10, 3-11.

Downie, C. 1982. Lower Cambrian acritarchs from Scotland, Norway, Greenland and Canada. - Trans. Roy. Soc. Edinburgh: Earth Sciences, 72, 257-285.

Eklund, K. 1990. Lower Cambrian acritarch stratigraphy of the Bărstad-2 core, Ostergötland, Sweden. - Geologiska Föreningens i Stockholm Förhandlingar, 112, $1,19-44$.

Hagenfeldt, S. 1989. Lower and Middle Cambrian Acritarchs from the Baltic Depression and South-Central Sweden, Taxonomy, Stratigraphy and Palaeogeographic Reconstruction. Department of Geology. University of Stockholm.

Martin, F., Dean, W. T. 1988. Middle and Upper Cambrian acritarch and trilobite zonation at Manuels River and Randam Island, Eastern Newfoundland. - Geological Survey of Canada, 381, 1-91.

Moczydlowska, M. 1989. Upper Proterozoic and Lower Cambrian acritarch from Poland - Micropaleontology, biostratigraphy and thermal study. - Lund Publications in Geology, 75, Lund, Sweden.

Представил Э. Пиррус

Поступила в редакцию 4/IV 1991 


\section{ALAM- JA KESKKAMBRIUMI PIIRIKIHTIDE BIOSTRATIGRAAFIAST LEEDUS}

Uuritud piirikihtide intervall hõlmab setted Holmia tsooni ülaosast kuni Paradoxides paradoxissimus'e tsooni allosani. Leedus viimastel aastatel puurimistega avatud täielikud läbilōiked võimaldavad teha mikrofütofossiilide (akritarhide) levikuseaduspärasuste detailuuringuid ja nende põhjal täpsustada vaadeldavate kihtide stratigraafiat.

Autor soovitab määrata Rausve lademe alumine piir Eliasum llaniscum'i ilmumise järgi, Kibartai lademe oma Lophosphaeridium variabile ilmumise järgi. Paraku ei ole Kibartai lademe ülemine piir akritarholoogiliselt määratav, seetõttu moodustavad nad koos lasuva Deimena seeriaga stratigraafilise üksuse, mis on korreleeritav trilobiitide Eccoparadoxides oelandicus'e tsooniga. Keskkambriumi ülemised kihid sisaldavad iseseisva akritarhide koosluse ja on vaadeldavad Paneriai lademena, mis rööbistub tōenäoliselt trilobiitide $P$. paradoxissimus'e tsooni allosaga.

\section{Tadas JANKAUSKAS}

\section{BIOSTRATIGRAPHY OF THE LOWER AND MIDDLE CAMBRIAN BOUNDARY BEDS OF LITHUANIA}

The paper presents new data on the stratigraphical distribution of acritarchs in the transitional beds from the Lower to Middle Cambrian, obtained by studying the drill core section from the west coast of Lithuania.

The acritarch Volkovia dentifera was established for the first time in the Vergale Regional Stage, which can be correlated with the Holmia trilobite Zone of Poland of the Lower Cambrian. Earlier this species was known only from the younger beds of the Rausve Regional Stage (Волкова, 1973; Moczydlowska, 1989).

The lower boundary of the Rausve Regional Stage is defined by the first appearance of Eliasum llaniscum and some other taxa: Liepaina plana, Micrhystridium notatum, M. ex gr. lanceolatum, Baltisphaeridium pseudofaveolatum, B. latviense, Cristallinium ex. gr. cambriense (Fig. 1; . Table). The species Skiagia insigne, Alliumella baltica, Micrhystridium obscurum, Retisphaeridium howellii, Baltisphaeridium implicatum, very rarely recorded in the oldest deposits of the Vergale Regional Stage, may be numerous here.

The Kybartai microflora, occurring in a very narrow stratigraphical interval (Figs. 1,2) correlates with the Eecoparadoxides oelandicus trilobite stage of the lowermost Middle Cambrian and has much in common with the Rausve microflora. Here Micrhystridium notatum, Eliasum llaniscum, Baltisphaeridium pseudofaveolatum and Liepaina plana are predominating. Other species, transitional from the Lower Cambrian, though commonly present, are less abundant. Most of the Lower Cambrian acritarchs are not found here. For the first time only one species Lophosphaeridium variabile appears at the base of the Kybartai Regional Stage (Fig. 1, Table).

A very similar acritarch assemblage is present in the lowermost part of the Deimena Superformation, but in its upper part characteristic microfossils are lacking. The whole Deimena interval can be correlated with the E. oelandicus Stage only tentatively.

The Genčiai Member, the youngest Middle Cambrian unit of western Lithuania, has yielded numerous acritarchs. Timofeevia lancarae, $T$. phosphoritica, Cristallinium cambriense, Micrhystridium confusum. The same assemblage is present in the Paneriai Formation of the eastern part of Lithuania. Both these units belong to Paneriai Regional Stage and correlate with the lower part of the $P$. paradoxissimus trilobite stage. 